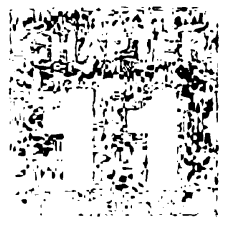

\title{
CHILDREN \\ LEARNING OUTSIDE THE CLASSROOM
}

\section{Louise Milne}

\section{INTRODUCTION}

Learning outside the classroom has the potential to extend a child's technological knowledge and promote design solutions to real-world problems. When a visit involves making a chocolate gift to celebrate Mother's Day, there are lots of opportunities for creative and original ideas that consider personal interests and the pupils' aspirations for creating a gift for their mother or relative.

\section{BACKCROUND}

The original study, from which this chapter is drawn, comprised a qualitative, case-study approach. The context, and the nature and age group of the participants, required an examination of literature from three areas of study: design and technology (D\&T), education outside the classroom (EOTC), and the nature and the characteristics of 5-year-old children. This provided the principles that underpinned a planning framework co-constructed by myself and the two teachers of the new entrant classes. Over a 6-month period, data was gathered during three phases of the study: first, preparation for the visit outside the classroom; then the visit to the chocolate factory and the subsequent development of the chocolate gift in the classroom; and finally exploring the children's enduring understandings that resulted from the visit. Data was gathered through a series of interviews with the children and their teachers, observations and the analysis of the children's work. In addition, the focus of this chapter required an examination of literature that explored creativity and how this may be fostered with young children. Further discussion is in Chapter 3. Interestingly, the key ideas of this investigation merged closely with the pedagogical approach employed to support the children in their technological practice and problemsolving.

\section{Enhancing creativity}

The origin of the term 'creative' has a long and constantly evolving history, and today there is widespread acceptance that 'creativity' is a difficult concept to define (Carter, 2004). 
Bruce (2011: 111) believes that "creativity in everyday life lifts living to levels of fulfilment, satisfaction, effective, deep and rigorous practical thinking which are in a different league to pedestrian, boring and commonplace living'. Being creative problem-solvers is apparent in many of the activities we carry out in our day-to-day lives, but interestingly, in the technology community of which I have been a part, there has been little commitment to untangling notions of creativity from what we understand to be the nature of technology and technology education. It could be said that in some regard therc has been no nced as they appear indivisibly connected, one overlapping the other. To borrow from the analogy of Gibbons and Johnston (1974) in which they described the relationship between science and technology, creativity, I believe, provides a pool of skill and talent from which the technologist can fish.

International curricula for primary-aged children generally support cultivating and supporting children's developing creativity. How then does this manifest in the 5-year-old's classroom? Bruce (2011) has written extensively on the subject of cultivating creativity with very young children. She argues that there is evidence to suggest that children born into families where they are exposed to music, dance or the visual arts from an early age, will experience an impact on their brain development. However, she also dispels the myth that creativity 'is a gift with which only some people are born' (Damasio, 1999: 1) and that young children can be helped from an early age to be 'courageous learners with a sense of adventure, able to take risks, dare to make mistakes and have a go, try alternatives, rearrange what they know or try out new ways of working' (Damasio, 1999: 7). A key element in this development is undoubtedly teacher knowledge - knowledge of how to nurture creative learning, how to build an environment in which children feel emotionally safe, willing to take risks, make mistakes and to break the rules of engagement (Bruce, 2011).

Howkins (2001) identifies five elements that he sees as integral to creative thinking - review, incubation, dreams, exciternent and reality checks. However, the application of these to the learning of 5-year-old children in D\&T offers another level of complexity to teacher planning. For example, it is likely that these children engage, possibly for the first time, in a technological problem that is proposed by their classroom teacher. Their early childhood experiences are likely to be individual or group activities that are supported, rather than directed, by the teacher, where the teacher/child ratio is lower and there is greater opportunity for children to pursue their own interests.

An example of the cognitive limitations these children experience is explained in Piaget's description of the 'intuitive sub-stage' child, the 4-7-year-old child, who is more likely to make decisions based on intuition rather than logic, who may develop representational skills of language, mental imaging and drawing to view the world, but only from his/her own perspective (Piaget, 1954). This may cause the child to ignore important information if tackling a technological problem, which concerns a person other than him/herself. The challenge for the teacher, therefore, is to plan and facilitate a technology project that is age-appropriate, has a limited number of variables for the child to consider, and involves a context that is of high interest (Chapter $\mathbf{4}$ has more on starting points).

\section{TEAGMERS' PLANNING OF Dat}

A 13-year-old student who participated in an early D\&T research project once stated that 'technology is having ideas and making them' (Ministry of Education, 1997). This is a simple and reasonably accurate description of what technology education is for young 
children, but for the technology teacher, a deeper understanding is required to inform their planning and their pedagogical practice.

There are four widely accepted categories for examining technology: technology as objects or artefacts, technology as knowledge, technology as activity, and technology as volition (de Vries, 2012; Jones et al., 2013). The category most relevant in this instance is 'technology as activity'. Here we see the first clear connection with creativity and creative response through design. de Vries (2012) identifies three components of 'technology as activities': designing, making and using and/or appreciating processes (De Vries, 2012: 22). Design and the process of designing a product is a key component of D\&T. It is defined in a number of ways and may describe a preliminary drawing for something that is to be made; it may describe a period of time, for example, the Arts and Crafts movement of the late 1800s; or it may describe a process of product development from initial concept through to its final realisation.

'Technology as activity' is presented in D\&T in a number of curricula throughout the world. Of interest in this discussion is how this is addressed when working with new entrant children, the 5-year-olds. D\&T naturally draws knowledge and skills from other curriculum areas. Five-year-old children are at an early stage of language development, and within a technology unit most activities will include discussion, supported plamning and investigations, with limited expectations for independent reading and writing. The duration of a technology unit, often positioned as part of other learning, is typically spread over one to two weeks. Within this period, the children would develop an understanding of the technolugical problem to be solved, and importantly, who was to receive their final solution. With the help of their teacher they would create a plan, and begin to investigate the context and the possible design solutions for their final product. An important goal is to produce an outcome that is fit-for-purpose and this often requires the children to carry out some simple market research - typically employing simple text, images and emoticons (Ministry of Education, 2010).

Pedagogically, there are a number of challenges that teachers face when teaching D\&T to S-year-old children; for example, their design capabilitios and their limited understanding of the continuous process required to complete a final outcome. It is recognised by a number of researchers investigating primary children's technology that their understanding of the purpose of a technology brief can easily be lost in the multitude of activities in a busy classroom programme (Moreland and Cowie, 2011). Moreland and Cowie (2011) discuss this in terms of maintaining a sense of continuity and connectedness when tcaching technology to this younger age group. These children are known to have difficulty recognising that each phase of their work is not an end-point in its own right but rather one step in a more extensive process. Their design drawings are a good example of this. Young children may complete their drawn designs and then either disregard them when constructing a final outcome or take them home to share with the family, rather than keeping them at school and using them to help in the construction of their product (Rogers and Wallace, 2000). Fleer (2000) noted that young children do not understand the purpose of design drawings, what information they should contain or how they should be constructed. Rogers and Wallace (2000) emphasise the need for children to understand the difference between drawings that explain, as in a plan, and drawings that depict, as in a piece of art work. This research suggests that where children are able to conceptualise the difference between the two, the task of creating a design drawing is more likely to merge with the process of technological development and give it greater meaning and purpose. 


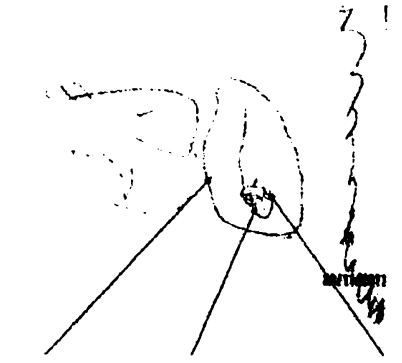

The ute

The wheel

The seat for Grandad

$$
1
$$

The other whed

Mame: What are you drawing?

Nex I drew a ute. there's a seat for Grandad and a wheel But where do I purt the other wheel? Mame: What do you mean?

Alex the one you can't see. I know. (Alex turns page, drows wheel, and smies) There!

18: Imaghation required to make out all aspects of the picturel (like the ver tical grassl)

Figure 11.1 A pre-schooler's drawing showing her awareness of 3D

However, a further challenge for young children planning a three-dimensional structure is their inability to draw in three dimensions. While there is evidence that young children are aware of the three-dimensional nature of structures, they have difficulty expressing this through their drawings (Jolley, 2010). An example of this is shown in a drawing by Alex, a 3-year-old attempting to draw her grandfather's farm vehicle (see Figure 11.1). After drawing the body of the vehicle, she was unsure where to draw the wheel that was on the other side of the vehicle but which she could not see. Her solution was to turn the page over and draw the wheel on the back of the paper (A. Milne, personal communication). Further discussion on drawing is in Chapter 6.

The expectation for young children to include design drawings in their D\&T projects has been extensively challenged by researchers. Their ability to translate a threedimensional structure into a two-dimensional drawing requires higher-level thinking and abilities, and this is generally beyond the capabilities of the 5-year-old child. As a means of resolving this issuc, the early research carried out by Golomb (1989) suggests that children's design thinking can be enhanced if they are encouraged to communicate their design ideas by using a three-dimensional medium such as clay or plasticine. This avoids the constraints of managing a two-dimensional medium in order to communicate a threedimensional structure, particularly as it relates to planning, positioning and alignment.

In general, the technological process of 5-year-old children is one that lies somewhere between the exploration goals of their early childhood experiences and the achievement goals of their primary school curriculum. The children's practice will tend to focus on one 
solution and generally lack iteration or review. Design drawings can be encouraged, but left alone, children are most likely to experiment with materials in order to find a solution to their problem, rather than sketch their ideas. While this may appear to hamper their design thinking, research suggests that the most important clement that impacts on the breadth of their ideas, is the experience and exposure they have to the relevant field of inquiry (Carter, 2004), that is, gaining knowledge that will provide them with the information they require to develop a solution. In this study, this was knowledge of chocolate and chocolate-making.

\section{EDUCATION OUTSIDE THE CLASSROOM (EOTC) AS A CONTEXT FOR GHILDREN'S CREATIVE PROBLEM-SOLVING}

EOTC is a generic term used to describe the curriculum-based learning and teaching in schools that extends beyond the four walls of the classroom. Ideally, these experiences should provide links between children's classroom studies and the real world in which they live. They should include activities that are hands-on, interactive and have the potential to enrich the learning opportunities provided in the classroom (Ministry of Education, 2010).

Falk and Dierking (2000) describe leaming experiences outside the classroom as 'a whole-body, whole-brain, whole-experience activity' (Falk and Dierking, 2000: 10). They developed the Contextual Model of Leaming, which consists of three overlapping contexts: the personal, the socio-cultural and the physical (Falk and Dierking, 2000). When planning a visit, the personal context highlights the motivation and expectations of the children, understanding something of the children's prior knowledge, their interests and beliefs, and providing levels of choice and control in the direction that the study will take. The sociocultural context includes within-group socio-cultural mediation and facilitated mediation by the teachers, site staff and parent-helpers. The physical context includes the children having knowledge of how the visit will be organised, what to expect when they get there, and teaching time given to reinforcing events and experiences after the site visit (Falk, 2004). A fourth dimension of 'time' was also added to the Contextual Model, as further research indicated that random events could occur during a visit, which internupt the experience and were likely to impact on the quality and quantity of visitor learning. Here we can see a direct overlap of ideas described in the eartier section where creativity and the 5-year-old child was discussed.

The type of learning most commonly associated with learning outside the classroom is informal learning. Falk and Dierking's concept of 'perceived choice' (Falk and Dierking, 2002), instead of informal learning or free-choice learning, resonates well with the visit that was enacted as part of this study. While a set of predetennined learning intentions from the curriculum was selected by the teachers, the participants were motivated by a 'need to know' factor (Lambert and Balderstone, 2000), that is, the children needed to find out how to make a chocolate gift for their mother. They were also motivated by a very predictable interest in the chocolate-making context. It was anticipated that the children might approach the visit with a sense of freedom to selcct or take note of items that appealed to them and processes they thought would have relevance to their task of making a chocolate gift. In effect, they were to decide when, where and what to learn.

The early work of Falk and Balling (2001) describes the most valuable and memorable leaming experiences outside the classroom as 'novel' experiences - those that are 
new, and of high interest. In their research on the long-term memories of visitors to world expositions, Anderson et al. (2003) argue that 'memories were overwhelmingly dominated and mediated by the socio-cultural identity of the individual at the time of the visit' (Anderson et al, 2003: 407). The lens through which the experience is viewed strongly influences what is noticed and remembered. For example, the interests of five-year-old children will have an effect on what attracts their attention and what is ignored. This may not relate well to the learning intentions identified by the teachers. Also aligned with the success of an experience outside the classroom is the children's enjoyment of the visit. Interestingly, by experiencing an emotional connection with the experience - that is, excitement, wonderment, amusement and even shock - it is likely that the children's memories of the event will be increased (Anderson et al., 2003).

In order to maximise children's learning opportunities at sites away from the classroom, there are a number of key features to consider. Falk and Balling (2001) refer to settings that should be of appropriate novelty. Sites should provide children with new, interesting and clearly discriminable events or activities, without the distraction of irrelevant stimuli or overly lengthy visits. Not all sites will suit all age groups and so it is important that teachers select sites for children that offer an age-appropriate experience. Falk and Balling (2001) suggest that young children may gain value from very short forays away from the classroom, rather than the usual 'day trip', if leaming is to be the primary intent of the day. A teacher's reason for taking children on a visit can be viewed as the most important decision when planning a leaming experience outside the classroom (Rennie and McClafferty, 1996). Similarly, the children's understanding of why they are going on the visit is equally important, as this will impact significantly on their learning outcomes.

Selecting a suitable context for the children to experience D\&T is best achieved by finding design opportunities that emerge from their everyday lives, at home, at school or from within their community. Being familiar with the context enables the children to engage in it with greater confidence, to understand more about the requirements of the user and to critique their final outcomes. Table 11.1 shows some possible examples.

The following section describes how the elements of D\&T, EOTC and nurturing children's creativity wore incorporated into the fourth D\&T unit listed in Table 11.1. Two classes of 5-year-old children participated in the unit during which they investigated, designed and then created a chocolate gift for Mother's Day.

Table 11.1 Real-world opportunities for teaching D\&T

D\&T Focus

Education Outside the Classroom

Designing and making pop-up cards to celebrate a special occasion, e.g. the teacher's wedding

Designing and making frulty muffins to welcome the children on their visit from the local pre-school

Designing a new plece of equipment for the junior school playground

Designing and making a chocolate gift for Mother's Day
A visit to a local greetings card manufacturer

A visit to a local bakery

A visit to a local playground with the playground engineer

A visit to a local chocolate-making factory 


\section{NURTURING THE GREATIVE RESPONSES OF CHILDREN TO TECHNOLOQIGAL PROBLEM-SOLVING}

Planning a teaching unit that incorporated EOTC and D\&T reflected the cognitive apprenticeship model that is associated with teaching D\&T - the concept of working alongside an expert in order to respond to a tochnological problem. The D\&T unit developed by the teachers and me comprised three phases: preparation for the visit to the chocolate factory, the visit to the factory and follow-up tasks, and finally the design and construction of the children's gift for Mothers' Day. Each of these phases is described in a table (see Tables 11.2 11.4) with an accompanying paragraph to explain how the plan was drawn together so that it reflected the key components of each of the identified domains, the characteristics of the 5-year-old children, D\&T, EOTC and children's developing creativity.

Prior to examining the detail of the plan, a general observation is that, while the disposition of individual children impacts significantly on how they will respond to any given situation, the pedagogical approach of the teachor and his/her ability to create a nurturing learning environment will have significant bearing on how a child engages with the opportunities available to them. Bruce (2011) referred to this type of environment as

Table 11.2 Teaching sequence phase one

1. Establish scenario and guide discussion regarding Mother's Day being celebrated shortly and chocotates often given as a gift.

2. Establish problem, e.g. 'How can we make chocolates for a gift that are safe to eat and that are Mum's favourite?'

3. Establish what children need to know in order to solve problem. This should lead into need to find an expert or vist an expert, e.g. Candyland.

4. Establish what children would like to know about chocolates.

5. Find out what children's existing knowledge is about the chocolate-making process - draw a small sequence of pictures showing how they think chocolate might be made.

6. Brainstorm what chidren know about the different types of chocolate, e.g. dark chocolate, milk chocolate, coloured chocolate, shapes and fillings. Chart these for reference later (see Figure 11.2).

7. Teach the chocolate-making process from the futt of the cacao tree to the production of large blocks of bulk chocolate for use in factories.

8. Brainstorm/teach children about the different types of chocolate you can buy. Taste-test a range of chocolate flavours.

9. Discuss how chocolates might be designed, e.9. adding colour.

10. Think about what they would like to make and how they might do that. This should lead into declding what questions they will need to ask at Candyland.

11. Explain the programme for the visit to children, e.g. the chocolate-making presentation, the lollipop-making presentation, and the investigation in the shop of the different types, shapes and colours of chocolates. 


\section{Androw}

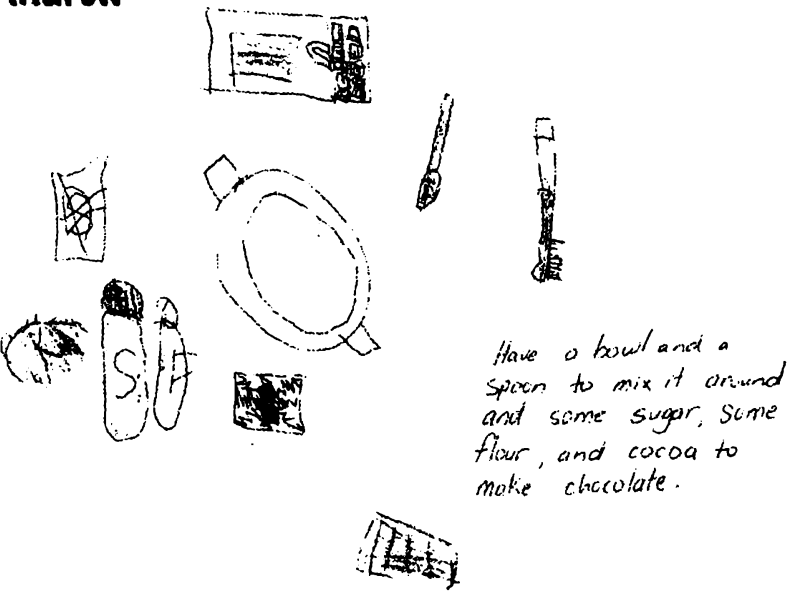

Flgure 11.2 An example of a child's prior knowledge of making chocolate

one that creates 'courageous learners', the children who feel supported, emotionally safe to take risks and demonstrate a willingness to try new ways of doing things (Bruce, 2011: 7). The research teachers in this study were adept at creating an environment that was both engaging and empowering.

\section{(i) Preparation for the visit}

Carter (2004) reminds us that, in this context, knowledge of chocolate and chocolate-making is not sufficient in itself to assure a creative response to the children's problem. However, this information-gathering phase of the teaching plan was critical. It introduced the context, presented the problem to be solved and established the purpose of the visit to the factory. It provided an opportunity for the teacher to understand something of the children's prior experiences in relation to the context, and enabled her to build on these experiences so the children had ideas and experiences to draw on when creating their design solutions. This was the phase that incorporated Howkins' (2001) stages of creative thinking during which children review, incubate, dream and gather excitement as they begin to consider how they might create their chocolates for Mother's Day. They built an extensive knowledge of chocolate and chocolate-making by taste-testing different types of chocolate, reading stories and viewing video clips of where the cacao bean is sourced. The language of chocolate-making was emphasised and the children understood something of how the beans 
were collected, ground, mixed and made into the bulk chocolate that they would see being used at the factory. As a result of the preparation they experienced, the children generally understood the purpose of the visit and were able to go to the factory understanding that there was a job to do - as Lambert and Balderstone state (2000), the children were armed with a 'need to know' focus, and the 'incubation' phase (Howkins, 2001) of their creative design ideas was in motion.

\section{(ii) The visit to the factory and follow-up}

This phase of the children's technology project can be likened to Howkins' 'reality checks' in which the children see for themselves the process of making chocolate, the extensive

Table 11.3 Teaching sequence phase two

1. Children organised into small groups with one parent-helper to supervise. Travel to venue.

2. Children and parent-helpers assemble outside Candyland for morning tea. Children move through factory visit with parent-hetper. Parents interpret activities and emphasise key points. Endeavour to keep children focused and on-task - $\theta . g$. finding out how to make a chocolate glft for Mum.

3. Prompt children to ask their prepared questions and any others that may arise.

4. After the chocolate-making demonstration, parent-helpers take children to the retall shop to look at the different types of chocolates. Use the correct terms and encourage children to look at labels. Talk about how the products have been made, $\theta .9$. adding colouring or flavouring.

5. Look at the moulds available in the shop. (This is important as the children will need to consider these when they design their own chocolate gift.)

6. After the visit, talk about the chocolate-making process the children observed at Candyland using a sequence of photographs to support thelr ideas. Ensure the language of the experience is used, $\theta .9$. the ingredients, the processes, the machines, the stages of production, e.g. syrup, moulds, etc. Spend time re-sequencing the activities so they understand that a specific process is important.

7. Children draw a picture showing what they learnt about the chocolate-making process.

Encourage them to talk about their drawings and, if they can, draw simple labels showing the names of the equipment and ingredients.

8. Discuss hygienic practices and the reasons for this. Link to the visit, mentioning the hand washing, use of gloves and other speclal clothing. Maybe share stories of food poisoning?

9. Brainstom all the possibllities for the look (and filling) they have for their chocolates. Do this on separate charts or in separate sessions.

10. Discuss how the chlldren will find out what thelr mothers like best when choosing chocolates and how they could remember her ideas, so they can design their chocolate gift. Introduce the simple questionnaire for them to fill in for homework.

11. Brainstorm/teach children about the different fillings that you can put inside chocolates. Carry out simple taste-testing with a range of chocolates and fillings as background knowledge for them - remembering who they are making the chocolates for. 


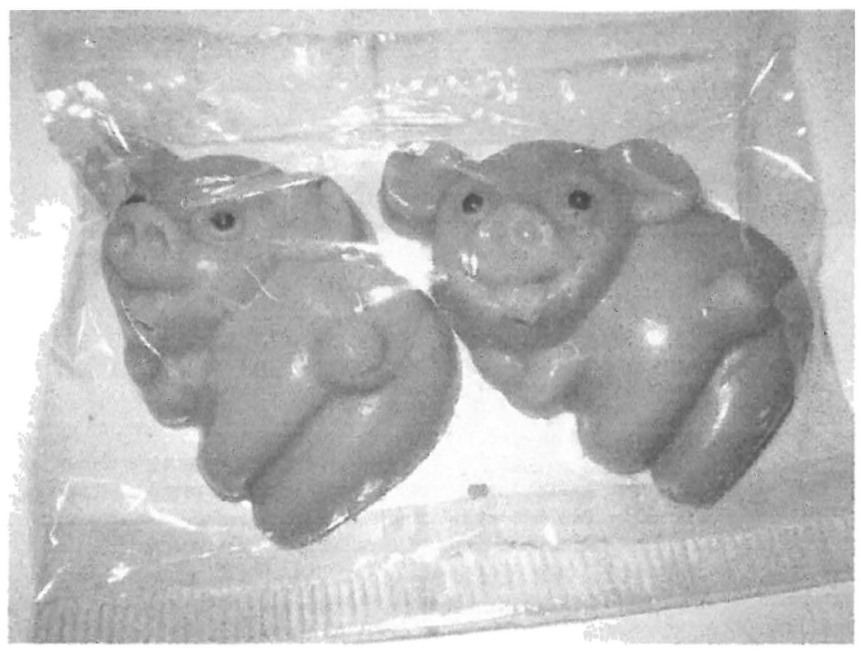

Figure 11.3 An example of chocolates on display

range of possibilities and a glimpse of what the limitations might be when they attempt to fashion their own designs in their classroom. The role of the parent-helpers who accompanied the children on their visit was very influential. They were responsible for keeping the children focused on their task, reiterating the language of chocolate-making, and ensuring that key phases of the chocolate production observed in the factory were not overlooked in the excitement of the visit. This increasingly enabled the children to talk about and better understand each of the development phases they viewed during the tour.

The retail shop had a key role to play in extending the children's design ideas, and the parent-helpers spent a good portion of time encouraging the children to examine the shapes, colours, fillings and toppings as well as the equipment that was needed to create a chocolate design. The laughter and excitement that reverberated around the room as they peered into the display cases (sce Figure 11.3) confirmed the high level of engagement and interest being experienced by the children. It was also an effective way of extending the possibilities for the children's design ideas for their gift.

\section{(iii) The design and construction of the gift for Mother's Day}

The impact that the visit to the factory had on the children's design ideas was significant. A comparison of the data gathered prior to the visit and the children's drawings and models 
Table 11.4 Teaching sequence phase three

1. In small groups, discuss/'analyse' the data they collected from their questionnalres.

2. Discuss the purpose of making a drawing or model of their chocolate gift, l.e.

(1) to help them declde what thelr chocolate gift might look llke, and

(ii) to show the teacher what they want to make so equipment and ingredlents can be prepared.

3. Using clay or other 3D medium, experiment with shapes, sizes and patterns which would be appropriate for Mum's chocolates.

4. Develop a procedural chart as a class to show how the chlldren will make their own chocolates. Discuss the use of moulds and a safe way they could fill them with the warm chocolate. (Refer to tecturique used at Candyland).

5. Dlscuss how children might add in extras, e.g. a filling or topping (piece of flake or swill, etc.)

6. Teacher prepares equipment and space for the chocolate-making. In small pre-arranged groups, children prepare to make their chocolate gitt (myglenic practices ... ), ofiscuss their designs, revisiting their models and questionnalre, and then pour their moulds. Add extras. Try to keep the children as involved as possible in discussions and make surficient chocoletes for them to taste-test themselves, show the class and stif leave some for Muml Keeping to plans is not critical.

7. In groups, children taste-test their finished products and draw their chosen emoticon on a chart. Writers can add a written comment. Encourage them to think about thet 'data' regarding Mum's preferences and whether they think they achleved it. If they think they didn't achieve it, What might they need to do another time - a simple reflection of the Intended outcome and an opportunity to problem-solve outcomes which were not as they intended.

8. Package chocolates in a simple cellophane bag or similar, to take home for Mum.

9. Follow-up discussions to reviow and reflect on their achievements.

revealed the extensive broadening of ideas that had occurred over the three weeks of the unit.

While the children's first interviews and drawings generally described chocolate as brown rectangles, their drawings and the clay and plasticine models created after the visit displayed a spectacular range of colours and shapes (see Figure 11.4). These included several hearts, a sun, a flower, a butterfly, a number of balloons, a worm, a fish, an icecream and, interestingly, a pair of red chocolate sunglasses 1

While the final outcomes created by the children were very satisfying and well received by their mothers, they did not necessarily reflect the data that was collected in their questionnaires, for example, the mother's preferred flavours and colourings. These outcomes emphasise one of the difficulties 5-year-old children experience when creating a produce for someone other than themselves. The 4-7-year-old child in the "intuitive substage' may struggle to view the world from the perspective of others (Piaget, 1954), creating products that they like themselves but willingly give to others. In saying that, the expansion of the children's design ideas is clearly evident, and the memory of the experience continued to be discussed by the children for the remainder of the year. 


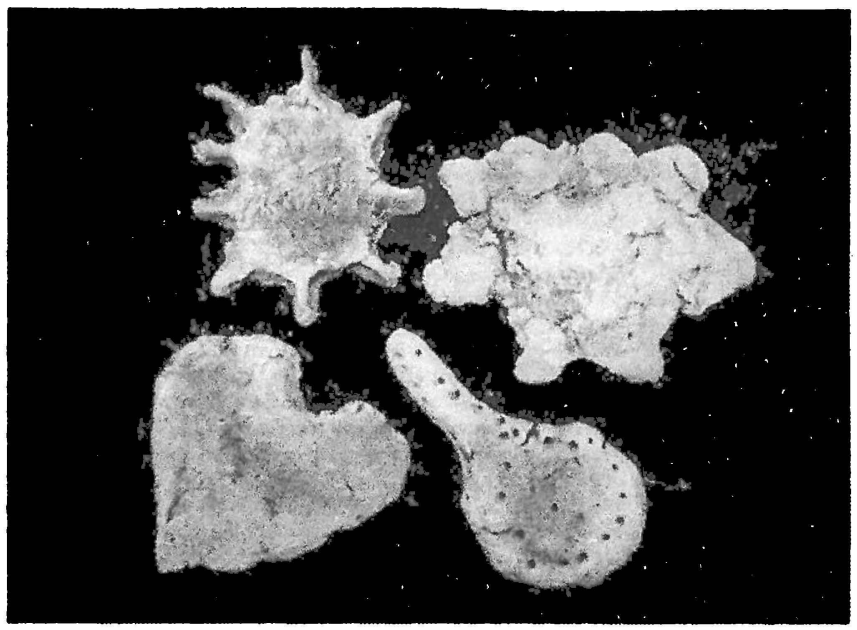

Flgure 11.4 Examptes of the children's clay models

\section{CONCLUSION}

Nurturing the creative thinking of 5-year-old children is fittingly summarised in Bruce's statement that 'creativity doesn't como from nowhere. It feeds off our experiences. It depends on the experience of life in order for creative ideas to develop' (Bruce, 2011: 78).

The literature of EOTC supports the notion of real-world contexts and real-world experiences, which, when linked to children studies within the classroom, can significantly impact on their learning (Dierking et al., 2003). This study, where the children investigated the practice of expert chocolate-makers at the factory, aligns with this philosophy. The context-specific language developed over the time of the teaching unit was robust, and where the children experienced repeated exposure to vocabulary after the event, the new language was retained as part of their everyday repertoire. The time given to preparing the children for the visit was validated by the confidence with which they engaged with the experience, and the relative ease with which they drew on and utilised new knowledge and design ideas. The children's ideas in this study broadened significantly from perceiving chocolate as small, brown rectangles, to chocolate as any colour or shape imaginable! An experience outside the classroom that is planned specifically for the 5-year-old child, and where time is given to both preparing them for the visit and following up the experience, has the potential to inspire an exciting, and at times surprising, array of creative ideas and satisfying technological outcomes. 


\section{REFERENCES}

Anderson, D., Thomas, G.P. and Ellenbogen, K.M. (2003) 'Learning science from experiences in informal contexts: the next generation of research'. Asia-Pacific Forum on Science Learning and Teaching, 4(1).

Bruce, T. (2011) Cultivating Crearivity for Babies and Children, 2nd Edn. London: Hachette. Carter, R. (2004) Language and Creativity: The Art of Common Talk. London: Routledge. Damasio, A. (1999) The Feeling of What Happens: A Lifewide Foundation. London: Heinemann. de Vries, M.J. (2012) 'Philosophy of technology', in Williams, P.J. (ed.) Technology Education for Teachers. Rotterdam: Sense, 15-34.

Dicrking, L.D., Falk, J.H., Rennie, L., Anderson, D. and Ellenbogen, K. (2003) 'Policy Statement of the "Informal Science Education" ad hoc committee'. Journal of Research in Science reaching, 40(2), 108-111.

Falk, J.H. (2004) 'The director's cut: toward an improved understanding of learning from museums'. Science Education, 88(1), 83-96.

Falk, J.H. and Balling, J.D. (2001) 'The field trip milieu: lcarning and behaviour as a function of contextual events'. Journal of Educutional Research, 76(1), 22-28.

Falk, J.H. and Dierking, L.D. (2000) Learning from Museums. New York: Alta Mira Press.

Falk, J.H. and Dierking, L.D. (2002) Lessons Without Limits: How Free-choice Learning Is Transforming Education. Walnut Creek: Alta.Mira Press.

Fleer, M. (2000) 'Working technologically: investigations into how young children design and make during technology education'. International Journal of Technology and Design Education, 10, 43-59.

Gibbons, M. and Johnston, R. (1974) 'The roles of science in technological innovation'. Research Policy, 3, 220-242.

Golomb, C. (1989) The Child's Creation of a Pictorial World: Studies in the Psychology of Art. Berkeley, CA: University of California.

Howkins, J. (2001) The Creative Economy: How People Make Money from Ideas. London: Penguin Press.

Jolley, R.P. (2010) Children und Pictures: Drawing and Understanding. Chichester, UK: Wilcy. Jones, A., Buntting, C. and de Vries, M.J. (2013) 'The developing field of technology education: a review to look forward'. International Journal of Technology and Design Education, 23(4), 191-212.

Lambert, D. and Balderstone, D. (2000) 'Fieldwork and tcaching', in Learning to Teach Geography in the Secondary' School. London: Routledge/Falmer.

Ministry of Education (1997) Towards Teaching Technology: Know How 2. Wellington, New Zealand: Leaming Media.

Ministry of Education (2010) Te Kete Ipurangi. www.tki.org.nz/ (accessed 27 February 2009).

Moreland, J. and Cowie, B. (2011) 'A matter of time: a temporal focus on teaching and learning primary technology', in Stables, K., Benson, C. and de Vries, M. (eds) PATT 25: CRIPT 8, London, UK: Goldsmiths, 302.

Piaget, J. (1954) The Construction of Reality in the Child. New York, NY: Basic Books.

Rennic, L.J. and McClafferty, T.P. (1996) 'Science centres and science leaming'. Studies in Science Education, 27, 53-98.

Rogers, G. and Wallace, J. (2000) 'The wheels of the bus; children designing in an early years classroom'. Research in Science and Technological Education, 18(1), 127-136. 